$21-28$

\title{
Treating thoracic-disc herniations: Do we always have to go anteriorly?
}

Authors Richard J Bransford ${ }^{1}$, Fangyi Zhang ${ }^{2}$, Carlo Bellabarba ${ }^{1}$, Michael J Lee ${ }^{3}$

Institutions ${ }^{1}$ Harborview Medical Center, Department of Orthopedics and Sports Medicine, Seattle, WA, USA

${ }^{2}$ Harborview Medical Center, Department of Neursosurgery, Seattle, WA, USA

${ }^{3}$ University of Washington, Department of Orthopedics and Sports Medicine, Seattle, WA, USA

Methods evaluation and class of evidence (COE)

\begin{tabular}{|c|c|}
\hline \multicolumn{2}{|l|}{ Methodological principle: } \\
\hline Study design: & \\
\hline Randomized contolled trial & \\
\hline Cohort study & - \\
\hline Case control & \\
\hline Case series & \\
\hline Statement of concealed allocation* & \\
\hline Intent to treat ${ }^{*}$ & \\
\hline Independent or blind assessment & $\cdot$ \\
\hline Complete follow-up of $\geq 85 \%$ & \\
\hline Adequate sample size & \\
\hline Controlling for possible confounding & \\
\hline Evidence class: & III \\
\hline
\end{tabular}

The definiton of the different classes of evidence is available on page 83.

\section{ABSTRACT}

Study design: Retrospective cohort study.

Objective: To determine if there is a difference in outcome and complications in surgically managed patients with thoracic-disc herniations (TDH) undergoing a modified transfacet pedicle-sparing decompression and fusion (posteriorly) compared to those undergoing anterior transthoracic discectomies (anteriorly).

Methods: Thirty-five consecutive operatively managed TDH underwent operative management between March 2003 and November 2009. Outcomes and complications were reviewed from patient records and x-rays assessing differences between those treated posteriorly and those treated anteriorly.

Results: Twenty-four patients underwent posterior management for 35 $\mathrm{TDH}$ and ten patients underwent anterior management for twelve TDH. Mean age was 50 years in both groups. Body mass index (BMI) averaged 28.8 in the anterior group and 32.0 in the posterior group. Follow-up averaged 38 weeks with four patients lost to follow-up (all posterior). Major complications secondary to surgery occurred in three patients $(30 \%)$ in the anterior group (pulmonary embolus, pneumonia, and wrong level surgery) and in seven patients (35\%) in the posterior group (seroma, misplaced instrumentation requiring revision, recurrence requiring an additional operation, and four infections). No neurological complications occurred and all patients noted improvement from baseline. Average length of stay was 7.3 days in the anterior group and 4.2 days in the posterior group $(P<.003)$. Final pain as assessed by visual analog scale (VAS) improved from 6.7 to 4.3 in the anterior group and 6.9 to 2.3 in the posterior group $(P=.05)$.

Conclusions: Complication rates are similar between groups and are approach related. Posteriorly managed patients had greater improvement in pain and shorter length of stay. 


\section{STUDY RATIONALE}

Patients with symptomatic thoracic-disc herniations (TDH) not amenable to conservative measures have classically been treated with a thoracotomy and anterior discectomy. A modified transfacet pedicle-sparing decompression and fusion has recently been proposed as an alternative option in the management of TDH [1]. A comparison between anteriorly based and posteriorly based approaches has not previously been done.

\section{OBJECTIVE}

The objective of this study is to determine whether there is a difference in outcomes and complications in patients treated with a posterior transfacet decompression and fusion compared to those treated with an anterior thoracotomy and discectomy for symptomatic TDH.

\section{METHODS}

Study design: Retrospective cohort study

Inclusion criteria: All patients with TDH treated with either a modified transfacet pedicle-sparing decompression and fusion or an anterior thoracotomy between March 2003 and November 2009.

Exclusion criteria: Patients with TDH who were treated operatively with other techniques such as laminectomy or complete costotransversectomy with corpectomy during this collection period were not included in this study.

\section{Patient population}

- Thirty-four consecutively managed patients with TDH met the criteria. Patients with radicular symptoms and/or pure axial back pain had a minimum of 6 months of conservative therapy prior to surgery. Twenty-four were treated posteriorly and ten were treated anteriorly (Fig 1).

- Treatment technique was based on surgeon preference and was not influenced by patient demographics or herniation location or type. Of eight fellowship trained spine surgeons, four used an anterior approach and four used a posterior approach (Fig 1).

\section{Interventions}

- The anterior technique consisted of a lateral transthoracic approach through the chest in the lateral position with the assistance of a thoracic access surgeon in all cases but one. Eight of the ten patients also underwent fusions; two had discectomies without fusion.

- The posterior technique consisted of a modified transfacet pedicle-sparing decompression and fusion in the prone position as previously described in detail by Bransford [1] in 24 patients. With this technique, there is no retraction of the neural elements and no sacrifice of the nerve roots and the pedicles are spared. All patients are instrumented with posterior pedicle screws and an interbody T-PLIF (Synthes, Paoli, PA) allograft placed into the disc space. 


\section{Outcomes}

- Major complications were defined as those requiring unanticipated additional surgery, infection, readmission, or life-threatening complications.

- Primary outcomes included a change in neurological status as graded by the American Spinal Injury Association (ASIA) spinal cord injury grade and motor score and change in pain.

- Pain was graded using a visual analog scale (VAS) as part of the patient intake forms and was recorded as a numerical number from 0-10. VAS was defined as general body pain as opposed to specifying for back pain, chest pain, or radicular pain.

\section{Analysis}

- Categorical baseline variables and complication rates were compared using a Chi-square test.

- Changes from preoperative to postoperative ASIA motor scores and VAS pain scores were compared within and between treatment groups using a two tailed t-test.

- Other comparisons including length of hospital stay, intensive care admission (ICU), and estimated blood loss (EBL) were analyzed using a two tailed t-test.

- We defined statistical significance as $P<.05$. Statistical analysis was performed using SAS 9.2 software (SAS Inc., Cary, NC).

\section{Fig 1 Patient sampling and selection flow chart}

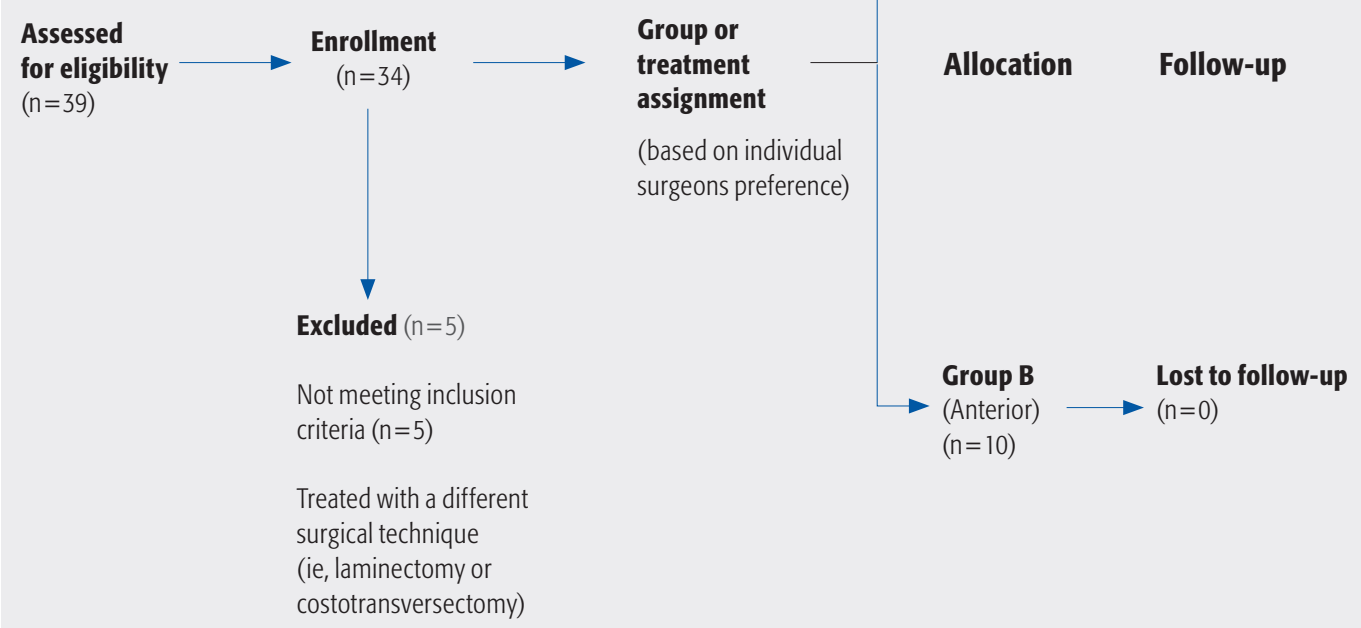




\section{RESULTS}

- Mean age (50 years), sex (70\% male anterior $/ 58 \%$ male posterior), BMI (28.8 anterior/32 posterior), and comorbidities were not statistically different between groups (Table 1).

- The overall follow-up rate was $88 \%$ (30/34) with $83 \%$ follow-up in the posteriorly treated group versus $100 \%$ in the anteriorly treated group. The mean followup was 41 weeks $(6-168)$ in the posteriorly treated group and 34 weeks $(6-112)$ in the anteriorly treated group.

- There was not a significant difference in EBL between the two groups. Average length of stay was $7.3 \pm 3.2$ days with I ICU day in the anterior group and $4.2 \pm 2.0$ days (excluding two with unusual circumstances) with 0 ICU days in the posterior group $(P<.003)$ (Table 2).

- No patient had a worsening neurological exam postoperatively and most with a motor score less than 100 improved by 3.2-3.4 points (Table 3).

- VAS improved from a mean of $6.7 \pm 1.4$ preoperatively to $4.3 \pm 2.5$ at last clinic visit in the anterior group and $6.9 \pm 3.2$ preoperatively to $2.3 \pm 2.0$ at last clinic visit in the posterior group $(P=.05$ for change from baseline to final follow-up between treatment groups) (Table 3).

- Major complications in those with follow-up occurred in three $(30 \%)$ of anteriorly treated patients and seven $(35 \%)$ of posteriorly treated patients and appeared to be related mainly to approach. The types of complications are outlined in Table 4.
Table 1 Demographic characteristics comparing treatment groups at study entry

\begin{tabular}{|c|c|c|c|}
\hline & $\begin{array}{l}\text { Posterior }(\mathbf{N}=\mathbf{2 4}) \\
\text { Mean (range) or } \mathrm{n}(\%)\end{array}$ & $\begin{array}{l}\text { Anterior }(\mathbf{N}=\mathbf{1 0}) \\
\text { Mean (range) or } n(\%)\end{array}$ & $P$-value \\
\hline Age (years) & $50.4(18-71)$ & $49.9(35-57)$ & .92 \\
\hline Male & $14(58)$ & $7(70)$ & .70 \\
\hline BMI & $32(24-47)$ & $28.8(18-42)$ & .25 \\
\hline \multicolumn{4}{|l|}{ Levels } \\
\hline $\mathrm{T} 1-2$ & 1 & 0 & .51 \\
\hline $\mathrm{T} 2-3$ & 1 & 0 & .51 \\
\hline T3-4 & 0 & 0 & 1.0 \\
\hline T4-5 & 1 & 0 & .51 \\
\hline T5-6 & 1 & 0 & .51 \\
\hline T6-7 & 2 & 3 & .06 \\
\hline T7-8 & 7 & 3 & .67 \\
\hline Т8-9 & 6 & 1 & .32 \\
\hline T9-10 & 3 & 3 & .11 \\
\hline T10-11 & 3 & 1 & .84 \\
\hline $\mathrm{T} 11-12$ & 10 & 1 & .41 \\
\hline \multicolumn{4}{|l|}{ Comorbidities } \\
\hline Morbid obesity & $5(21)$ & $2(20)$ & 0.96 \\
\hline Diabetes & $3(13)$ & $2(20)$ & 0.62 \\
\hline COPD* $^{*}$ & $2(8)$ & $2(20)$ & 0.56 \\
\hline $\begin{array}{l}\text { Mean follow-up } \\
\text { (weeks) }\end{array}$ & $41(6-168)$ & $34(6-112)$ & 0.65 \\
\hline
\end{tabular}

* Chronic obstructive pulmonary disease.

Table 2 Immediate postoperative measures comparing treatment groups

\begin{tabular}{lccc}
\hline & Posterior (N=24) & Anterior $(\mathbf{N}=\mathbf{1 0})$ & $\boldsymbol{P}$-value \\
\hline Measure & Mean \pm SD & Mean \pm SD & \\
\hline EBL Total (cc) & $740 \pm 812$ & $691 \pm 371$ & .86 \\
\hline EBL per level (cc) & $493 \pm 524$ & $633 \pm 346$ & .4 \\
\hline Length of stay & $4.2 \pm 2.0^{*}$ & $7.3 \pm 3.2$ & $<.003$ \\
\hline
\end{tabular}

* Refer to online appendix for explanation of two patients excluded in LOS from posterior group. 
Table 3 Comparison of neurological and pain outcomes comparing treatment groups

\begin{tabular}{|c|c|c|c|c|}
\hline & \multicolumn{2}{|c|}{$\begin{array}{c}\text { Pain } \\
\text { (VAS score) }\end{array}$} & \multicolumn{2}{|c|}{$\begin{array}{l}\text { Neurological } \\
\text { improvement } \\
\text { (ASIA score) }\end{array}$} \\
\hline & $\begin{array}{c}\text { Posterior } \\
\mathrm{N}=20\end{array}$ & $\begin{array}{c}\text { Anterior } \\
\mathrm{N}=10\end{array}$ & $\begin{array}{c}\text { Posterior } \\
\mathrm{N}=7^{*}\end{array}$ & $\begin{array}{c}\text { Anterior } \\
\mathrm{N}=6^{*}\end{array}$ \\
\hline Baseline (points) & $6.9( \pm 3.2)$ & $6.7( \pm 1.4)$ & $87.4( \pm 9.9)$ & $92.1( \pm 3.9)$ \\
\hline Follow-up (points) & $2.3( \pm 2.0)$ & $4.3( \pm 2.5)$ & $90.6( \pm 11.3)$ & $95.5( \pm 5.6)$ \\
\hline Change (points) & 4.6 & 2.4 & 3.2 & 3.4 \\
\hline $\begin{array}{l}\text { Within group } \\
P \text {-value }\end{array}$ & $<.0001$ & .01 & .67 & .37 \\
\hline $\begin{array}{l}\text { Between group } \\
P \text {-value }{ }^{\ddagger}\end{array}$ & .05 & & .98 & \\
\hline $\begin{array}{l}\text { Neurology was } \\
(\mathrm{N}=13) \text {. The re } \\
\text { preoperatively a } \\
+P \text {-value associat } \\
\text { each treatment } \\
\text { + } P \text {-value compari } \\
\text { and anterior app }\end{array}$ & $\begin{array}{l}\text { mpared in } \\
\text { aining patie } \\
\text { at final foll } \\
\text { with chan } \\
\text { bup. } \\
\text { baseline to } \\
\text { aches. }\end{array}$ & $\begin{array}{l}\text { ients with } \\
\text { had moto } \\
\text { v-up. } \\
\text { from basel } \\
2 \text { month c }\end{array}$ & $\begin{array}{l}\text { hotor score le } \\
\text { cores of } 100 \\
\text { to } 12 \text { montl } \\
\text { nges betwee }\end{array}$ & $\begin{array}{l}\text { s than } 100 \\
\text { within } \\
\text { posterior }\end{array}$ \\
\hline
\end{tabular}

Table 4 Comparison of complication rates between treatment groups

\begin{tabular}{lccc}
\hline & $\begin{array}{c}\text { Posterior } \\
\mathbf{N}=\mathbf{2 0} \\
\mathrm{n}(\%)\end{array}$ & $\begin{array}{c}\text { Anterior } \\
\mathbf{N}=\mathbf{1 0} \\
\mathrm{n}(\%)\end{array}$ & P-value $^{*}$ \\
\hline $\begin{array}{l}\text { Number of patients } \\
\text { with complications }\end{array}$ & $7(35)$ & $3(30)$ & .96 \\
\hline Infection $^{\dagger}$ & $5(25)$ & 0 & .08 \\
\hline Pneumonia $^{\ddagger}$ & 0 & $1(10)$ & .15 \\
\hline Wrong level surgery & 0 & $1(10)$ & .15 \\
\hline Recurrence & $1(5)$ & 0 & .47 \\
\hline Pulmonary embolism & 0 & $1(10)$ & .15 \\
\hline Implant complication & $1(5)$ & 0 & .47 \\
\hline
\end{tabular}

* Chi-square test.

† One patient with an infection developed osteomyelitis leading to a fracture which required a revision fusion.

$\ddagger$ Pneumonia with $1.5 \mathrm{~L}$ effusion.
Fig 2 Preoperative CT myelogram in 46-year-old woman with large calcified T8-9 thoracic disc herniation and myelopathy who underwent posterior decompresion. Fig $2 a$ sagittal cut and Fig $2 b$ axial cut.

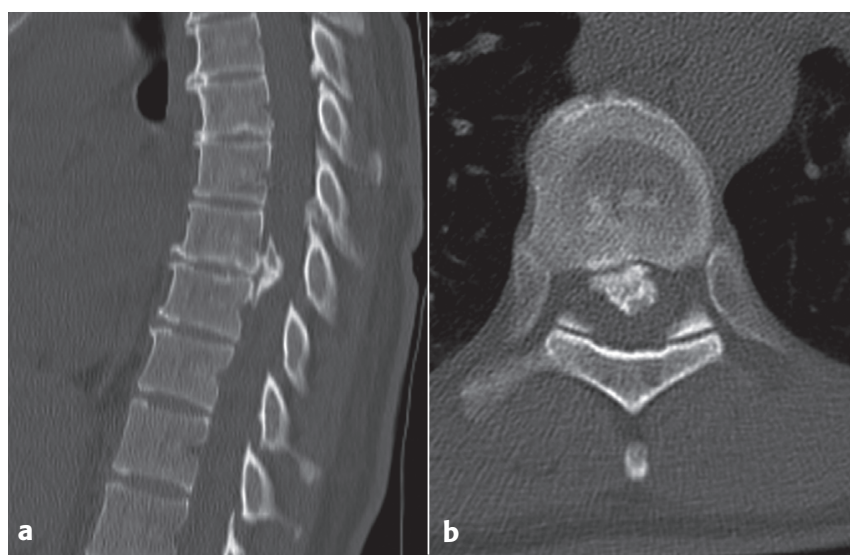

Fig 3a Intraoperative fluoroscopy images showing endplate shaver used to prepare the disc space for the graft and Fig $3 \mathrm{~b}$ intraoperative lateral showing placement of pedicle screws with T-PLIF allograft in disc space for patient presented in Fig 2.

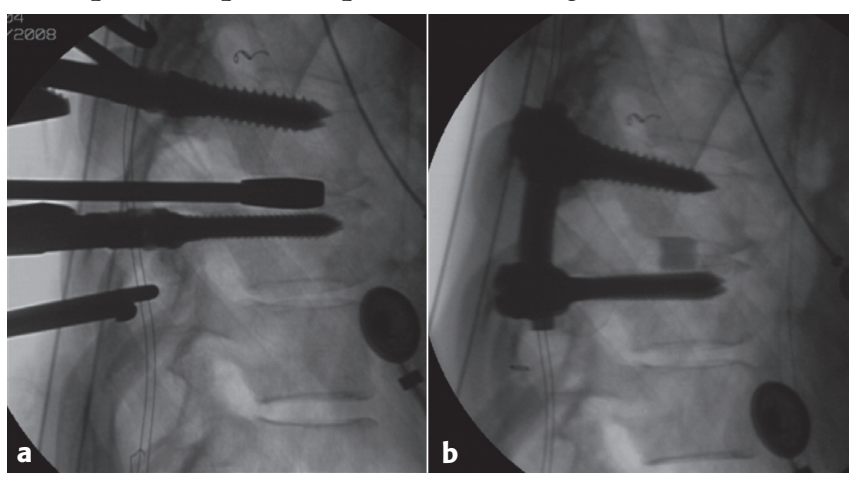

Fig 4 Postoperative CT scan demonstrating placement of instrumentation and placement of graft with excision of calcified thoracic disc for patient presented in Fig 2 and 3 (Fig 4a sagittal cut and Fig 4 b axial cut).

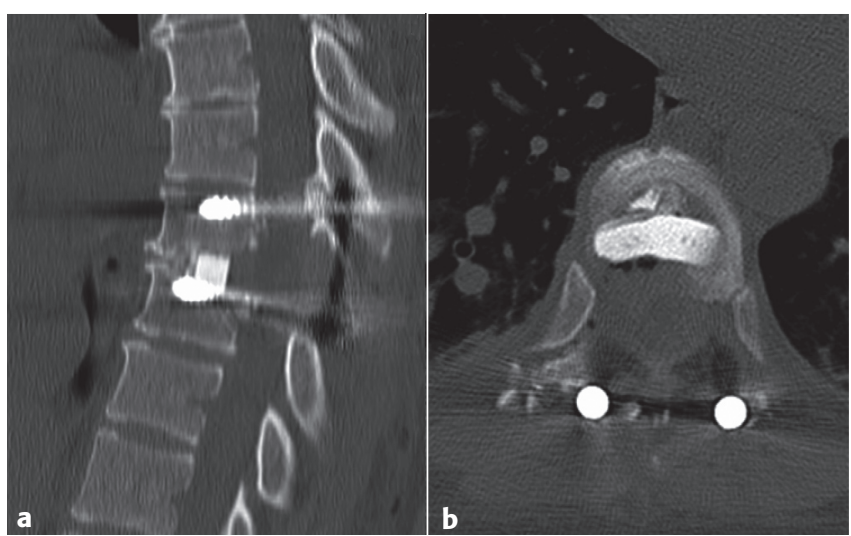




\section{Fig 5 Preoperative MRI of 56-year-old woman with T9-10 thoracic disc herniation and myelopathy who underwent an anterior decompression. \\ Fig 5 a sagittal cut and Fig $5 b$ axial cut}

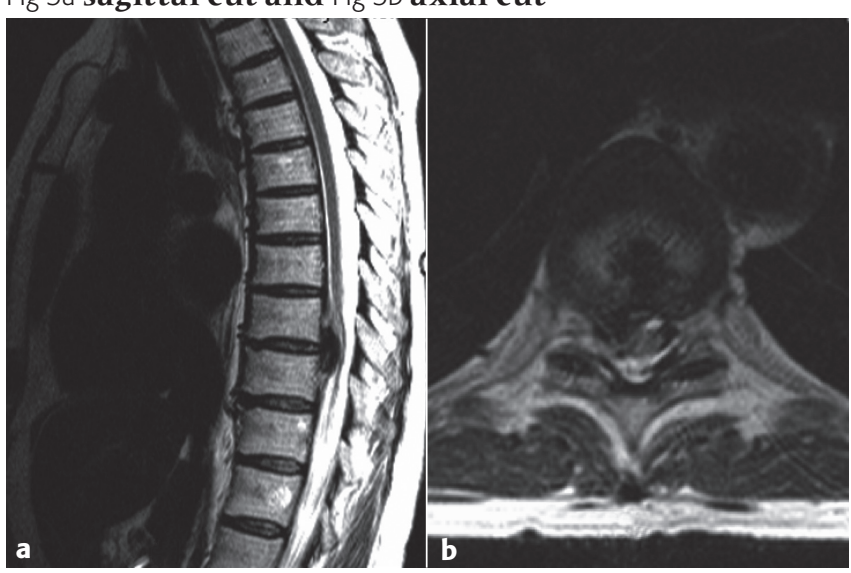

Fig 6 Postoperative AP (Fig 6a) and lateral (Fig 6b) $\mathbf{x}$-rays demonstrating placement of anterior graft and instrumentation in patient with images presented in

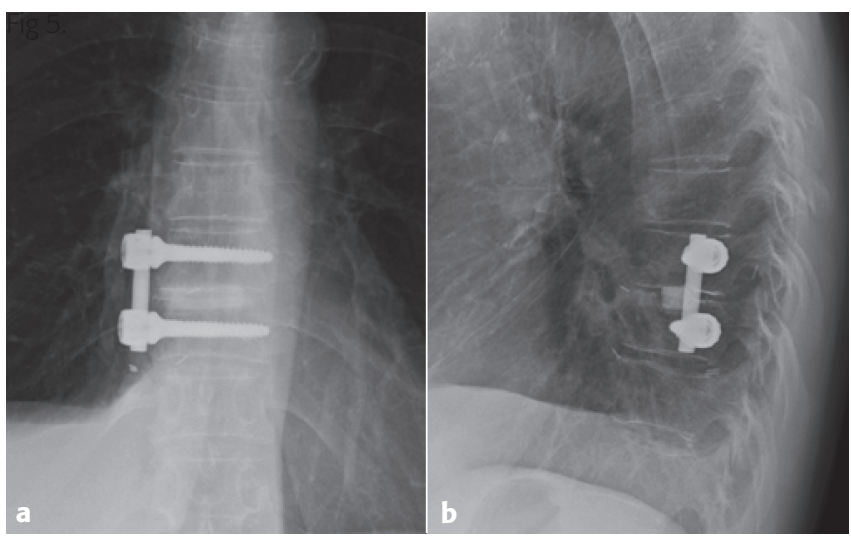

Fig 7 Visualization of transfacetal thoracic discectomies can be enhanced by use of an arthroscope. This patient received a thoracic discectomy at T7-8. Completeness of decompression was verified with a $70^{\circ}$ arthroscope under dry technique.

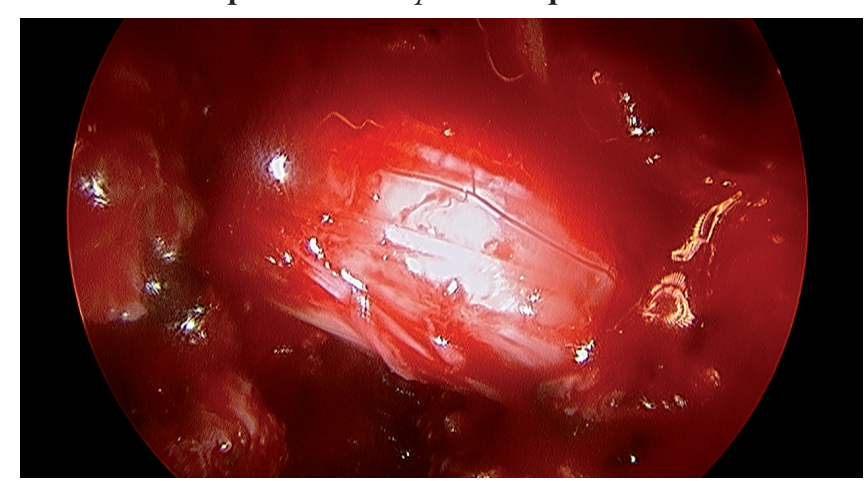

\section{DISCUSSION}

- Thoracic disc herniations are rare in comparison with their cervical or lumbar counterparts and are thought to comprise $0.1-4 \%$ of all disc herniations $[2,3]$.

- Anterior transthoracic decompressions of thoracic disc herniations are considered the gold standard [4-7], but this has not been compared with a posterior transfacet posterior decompression and fusion with respect to outcomes and complications. There are a limited number of retrospective case series discussing operative management. [1, 8-18] (Table 5).

- Strengths: This is the first study comparing transthoracic anterior discectomies to posterior transfacet pedicle sparing discectomies in the management of thoracic disc herniations.

- Limitations: This is a retrospective study with a relatively small sample of patients. There is the possibility that the small sample size may have limited the power to make meaningful comparisons, particularly of major complications. There is also the possibility that the follow-up of 41 weeks in the posterior group versus 34 weeks in the anterior group may have biased the outcomes of VAS improvement and motor score improvement. Another limitation is the $17 \%$ loss to follow-up in the posterior group compared to $0 \%$ in the anterior group; this unequal balance in loss to follow-up may influence the outcomes if those lost to follow-up were more likely to have improved or have had poorer outcomes.

- Since individual procedures were based on surgeon preference, there is the possibility of bias. However, each of the eight surgeons chose only one of the techniques which was their standard of care for management of all thoracic disc herniations. Baseline differences such as BMI, level of herniation, type of herniation, and comorbidities were unlikely to have confounded the interpretation of the outcome comparisons, though a stratified analysis or multiple regression was not possible to control for these factors due to the small sample size.

- Both techniques allowed for adequate decompression and equal improvement neurologically. There was a statistically longer length of stay in the anterior group compared to the posterior group. There was greater improvement in pain as measured by VAS in the posterior group compared to the anterior group.

- Each technique appears more susceptible to complications related to the approach. 
Table 5 Table of published retrospective case series describing operative management of thoracic disc herniations

\begin{tabular}{|c|c|c|c|c|c|c|}
\hline Posterior & Year & $\mathbf{N}^{*}$ & Approach & Complications n (\%) & Neuro deterioration $\mathbf{N}(\%)$ & Class of evidence \\
\hline Maiman [8] & 1984 & 23 & Lateral extracavitary & $0(0 \%)$ & $0(0 \%)$ & IV \\
\hline Simpson [9] & 1993 & 21 & Costotransversectomy & $0(0 \%)$ & $0(0 \%)$ & IV \\
\hline Le Roux [10] & 1993 & 20 & Transpedicular & $1(5 \%)$ & $0(0 \%)$ & IV \\
\hline Levi [11] & 1999 & 35 & Transpedicular & $2(5.7 \%)$ & $1(2.9 \%)$ & IV \\
\hline Bilsky [12] & 2000 & 20 & Transpedicular & $3(15 \%)$ & $0(0 \%)$ & IV \\
\hline Bransford [1] & 2010 & 18 & Transfacet & $6(33 \%)$ & $1(5.5 \%)$ & IV \\
\hline Anterior & Year & $\mathbf{N}^{*}$ & Approach & Complications n (\%) & Neuro deterioration $\mathbf{N}(\%)$ & Class of evidence \\
\hline Otani [13] & 1988 & 23 & Transthoracic & $0(0 \%)$ & $0(0 \%)$ & IV \\
\hline Bohlman [14] & 1988 & 19 & Transthoracic & $2(11 \%)$ & $2(11 \%)$ & IV \\
\hline Fujimara [15] & 1997 & 33 & Transthoracic & $2(6 \%)$ & $0(0 \%)$ & IV \\
\hline Regan [16] & 1998 & 29 & Video assisted & $4(13.8 \%)$ & $0(0 \%)$ & IV \\
\hline Ayhan [17] & 2010 & 27 & Transthoracic & $6(21.4 \%)$ & $2(7.4 \%)$ & IV \\
\hline Combined series & Year & $\mathbf{N}^{*}$ & Approach & Complications n (\%) & Neuro deterioration $\mathbf{N}(\%)$ & Class of evidence \\
\hline \multirow[t]{5}{*}{ Stillerman [18] } & 1998 & 71 & 82 disc herniations & $12(14.6 \%)$ & $1(1.4 \%)$ & III \\
\hline & & 49 & Transthoracic & & & \\
\hline & & 23 & Transfacet & & & \\
\hline & & 8 & Lateral extracavitary & & & \\
\hline & & 2 & Transpedicular & & & \\
\hline
\end{tabular}

* Articles had to have a minimum of 15 patients in order to be included.

\section{SUMMARY AND CONCLUSION}

- Both treatments appear to improve pain and neurological status.

- There was a significantly shorter length of stay and a substantial improvement in pain with the posterior approach over the anterior approach.

- Complication rates are similar between techniques and are largely approach related. Infections appear to be more frequently associated with a posterior approach.

- Either technique is effective in decompressing the neural elements. Prospective comparative studies with larger samples which are designed to limit confounding and bias are needed to further determine the superiority of one technique over the other.

\section{REFERENCES}

1. Bransford R, Zhang F, Konodi M, et al (2010) Experience with treatment of thoracic disc herniation using a modified transfacet pedicle-sparing decompression and segmental fusion. Journal of Neurosurgery: Spine; 12: 221-231.

2. Arce CA, Dohrmann GJ (1985) Herniated thoracic disks. Neurol Clin; 3:383-392.

3. Ridenour TR, Haddad SF, Hitchon PW, et al (1993) Herniated thoracic disks: treatment and outcome. J Spinal Disord; 6:218-224.

4. Fessler RG, Sturgill M (1998) Review: complications of surgery for thoracic disc disease. Surg Neurol; 49(6): 609-618.

5. McCormick WE, Will SF, Benzel EC (2000) Surgery for thoracic disc disease. Complication avoidance: overview and management. Neurosurg Focus; 9(4): el3.

6. Mulier S, Debois V (1998) Thoracic disc herniations: transthoracic, lateral, or posterolateral approach? A review. Surg Neurol; 49(6):599-606; discussion 606-608. 
7. Vollmer DG, Simmons NE (2000) Transthoracic approaches to thoracic disc herniations. Neurosurg Focus; 9(4): e8.

8. Maiman DJ, Larson SJ, Luck E, et al (1984) Lateral extracavitary approach to the spine for throacic disc herniation: report of 23 Cases. Neurosurgery; 14(2): $178-182$.

9. Simpson JM, Silveri CP, Simeone FA, et al (1993) Thoracic disc herniation. Re-evaluation of the posterior approach using a modified costotransversectomy. Spine; 18(13): 1872-1877.

10. Le Roux PD, Haglund MM, Harris AB (1993) Thoracic disc disease: Experience with the transpedicular approach in twenty consecutive patients. Neurosurgery; 33(1):58-66.

11. Levi N, Gjerris F, Dons K (1999) Thoracic disc herniation. Unilateral transpedicular approach in 35 consecutive patients. J Neurosug Sci; 43(1):37-42.

12. Bilsky MH (2000) Transpedicular approach for thoracic disc herniations. Neurosurg Focus; 9(4):e3.

13. Otani K, Yoshida M, Fujii E, et al (1988) Thoracic disc herniation. surgical treatment in 23 patients. Spine; 13(11):1262-1267.

14. Bohlman HH, Zdeblick TA (1988) Anterior excision of herniated thoracic discs. JBJS (Am); 70(7): 1038-1047.

15. Fujimura Y, Nakamura M, Matsumoto M (1997) Anterior decompression and fusion via the extrapleural approach for thoracic disc herniation causing myelopathy. Keio J Med; 46(4):173-176.

16. Regan JJ, Ben-Yishay A, Mack MJ (1998) Video-assisted thoracoscopic excision of herniated thoracic disc: description of technique and preliminary experience in the first 29 cases. J Spinal Disord; 11(3): 183-191.

17. Ayhan S, Nelson C, Gok B, et al (2010) Transthoracic surgical treatment for centrally located thoracic disc herniations presenting with myelopathy: a 5-year institutional experience. J Spinal Disord Tech (e-pub ahead of print).

18. Stillerman CB, Chen TC, Couldwell WT, et al (1995) Experience in the surgical management of 82 symptomatic herniated thoracic discs and review of the literature. J Neurosurg; 83(6):971-976.

\section{EDITORIAL STAFF PERSPECTIVES}

This is a CoE III treatment study.

Bransford et al compare approaches to treating thoracic disc herniation, which is rare relative to cervical and lumbar herniations. This study provides an example of the challenges related to studying rare conditions, the primary and most obvious being small numbers of patients available for study and the long period of time required to accumulate enough cases to study. These factors make prospective studies (randomized controlled trials or traditional prospective cohort studies) more difficult to design and implement, and use of retrospective cohort studies or other study designs more appealing and feasible.

Timing: It may take a long time for a single surgical center to accrue a sufficient number of cases; however, changes in technology, treatment options and perspectives continue over that time period and may be rapid. Endoscopic transthoracic discectomy provides an example: After initial enthusiasm for it as a less invasive, more benign alternative to open transthoracic discectomy, lack of comparative studies or evidence of its effectiveness and safety in real life applications resulted in a rapid decline in its popularity. Thus, it may have been of questionable value to have this as an intervention arm in a lengthy or time-sensitive study.

Study design: With rare conditions such as TDH, or other instances where randomized controlled trials are not feasible or ethical, outcomes from methodologically rigorous nonrandomized cohort studies may provide the best approximation of what might be observed in RCTs. Such studies can take surgeon training and preferences and patient preferences into account. These studies must, however, have carefully defined exclusion criteria, and document and consider prognostic factors. In addition, the patient and surgeon preferences must be well understood [King]. Regardless of the study design chosen, attention must be given to methods of reducing bias and accounting for potentially confounding factors.

While single studies like the one by Bransford will not change the current standard of care (anterior transthoracic surgery) for symptomatic TDH causing cord compression, it provides a foundation for further study. A multi-center, collaborative study may provide an opportunity to aggregate a larger number of patients to further evaluate treatment options for TDH.

\section{Reference}

King M, Nazareth I, Lampe F, et al (2005) Impact of participant and physician intervention preferences on randomized trials: a systematic review. Jama; 293: 1089-1099. 